\title{
Concepções de Tempo e Ensino de História
}

Dilma Célia Mallard SCALDAFERRI

\section{RESUMO}

Apresentamos alguns aspectos do conceito de tempo, categoria básica, articuladora e estruturante do raciocínio histórico. Analisamos as possibilidades da apreensão desse conceito por crianças das séries iniciais do Ensino Fundamental. 0 conceito de tempo já está presente, há alguns anos, nas propostas curriculares do Ensino Fundamental. Entretanto, muitos docentes que atuam no ensino básico, geralmente professores generalistas sem formação em História, apresentam dificuldades para trabalharem com este conceito devido à grande complexidade e ao grau de abstração intrínsecos às noções de tempo. Esperamos que esse trabalho possa ser usado como um instrumento de análise por estudiosos que fazem proposições de pesquisas sobre a aprendizagem do conceito de tempo com alunos dos anos iniciais da escolarização.

Palavras-chave: tempo histórico, ensino de história, raciocinio histórico.

A noção do tempo histórico social, aquele que as sociedades humanas imprimem à época em que vivem, relacionando-o com o seu passado e o seu futuro, um tempo de simultaneidade de mudanças e permanências, é por demais abstrato e estranho à compreensão infantil.

0 tempo acompanha a vida das crianças e dos adultos, é parte integral de suas histórias, mas é um conceito de difícil entendimento, como bem expressa Santo Agostinho... "0 que é, por conseguinte, o tempo? Se ninguém me perguntar eu o sei, se eu quiser explicá-lo a quem me fizer essa pergunta já não saberei dizê-lo"... (Santo Agostinho, 1948: 346).

Você pode sentir o tempo entendê-lo, mas certamente terá dificuldades para explicá-lo em toda a sua complexidade, talvez por ser este abordado de modo diferente nas diversas áreas do conhecimento: Filosofia, Física, Geologia, Geografia, Biologia, História, Matemática, Psicologia, etc.

\footnotetext{
* Mestre em Educação pela UNINCOR. Professora de História. Pesquisadora do LABEPEH( Laboratório de Estudos e Pesquisas em Ensino de História da Faculdade de Educação e do Centro Pedagógico da UFMG)
} 
Para REIS (1994:14) há algo comum entre os diversos discursos ou dizeres sobre 0 tempo, todos partem de questões semelhantes para chegar às respostas mais diversas, umas complementares, outras excludentes. Eis a problemática: o tempo é um ser? É movimento? É noção, conceito, categoria? É objetivo ou subjetivo? É único ou plural? É finito, puro devir ou também eternidade? Tem direção, é seta, espiral, linear? É reversível ou irreversível? É contínuo ou descontínuo?

Segundo Pomian, qualquer investigação que se refira ao estatuto do tempo legitima certas questões e elimina outras como privadas de sentido.

A palavra tempo é notoriamente polissêmica; pelo que, ao ler obras dedicadas ao tempo, temos muitas vezes a impressão de assistir a um diálogo cujos participantes não se compreendem, uma vez que não conseguem fazer corresponder os mesmos objetos aos mesmos vocábulos. No entanto, às vezes sem o saber, eles falam frequentemente de diversos estratos da mesma arquitetura temporal, de tal modo que os intuitos de uns nem sempre são incompatíveis com os dos outros. ( POMIAN,1993:78).

Trazendo outra consideração para o âmbito desta discussão, diríamos com base nas contribuições teóricas de Peter Lee que:

tempo é um conceito de segunda ordem, uma categoria articuladora e contextualizadora dos conteúdos específicos de caráter temático da História. Em outras palavras, os conteúdos ou as categorias estruturantes podem ser tanto conceitos substantivos ${ }^{1}$, que ultrapassam ou demarcam o campo da pesquisa historiográfica (trabalho, cultura, poder), quanto conceitos articuladores e contextualizadores de segunda ordem, próprios à natureza do conhecimento histórico (tempo e espaço). Os temas são os conteúdos da disciplina de História. As categorias estruturantes são instrumentos de análise destes conteúdos temáticos (ORIENTAÇÕES CURRICULARES DE HISTÓRIA, PARANÁ, 2006, p. 17).

\footnotetext{
${ }^{1}$ De acordo com Peter Lee, os conceitos substantivos referem-se aos conteúdos imediatos do conhecimento histórico (trabalho, cultura, poder, democracia, Revolução Francesa, Renascimento, etc.). Os conceitos de segunda ordem referem-se aos critérios de verdade e plausibilidade deste conhecimento (objetividade crítica, complexidade causal, inferências ou provas históricas, documentos e à contextualização - tempo, espaço, narrativa histórica, etc.)
} 
Por conseguinte, neste trabalho o tempo será focalizado como conceito amplo, na perspectiva vygotskyana, uma palavra que requer significado ou entendimento, lembrando que, como qualquer outro conceito, é um ato do pensamento, uma generalização, que demanda um processo de construção, com base no desenvolvimento intelectual do indivíduo, que muda de sentido de acordo com o contexto de uso, conforme as vivências e experiências efetivas do indivíduo; conceito este que também sofre modificações ao longo da história da vivência humana.

0 conceito de tempo só será construído pela criança, progressivamente, em várias etapas do seu desenvolvimento, ela é capaz de distinguir o dia e a noite, sequenciar etapas de um acontecimento, apontar o antes e o depois pela percepção do tempo vivido, mas seguir o tempo vivê-lo não é compreendê-lo.

0 trabalho de Jean Piaget sobre a noção de tempo na criança, baseado nas etapas do desenvolvimento, tem servido de referência para se trabalhar 0 conceito de tempo no ensino de História para as séries iniciais do Ensino Fundamental.

Pela contribuição de Piaget e seus seguidores, percebe-se que a criança constrói progressivamente a noção de tempo, do concreto ao abstrato. Essa construção inicia-se no período sensório motor, aproximadamente do nascimento até os dois anos e vai ser concluída no período das operações operatório-abstratas, após os 11 anos.

A abordagem cognitiva de Piaget tem sido de grande utilidade para a formação do conceito de tempo, na Educação Infantil e nos ciclos iniciais do Ensino Fundamental, mas não o bastante. 0 trabalho com as noções de ordem, sucessão, duração e simultaneidade e de quantificação do tempo não é suficiente para assegurar, que o adolescente domine mais tarde o conceito de tempo histórico.

Somente depois de ultrapassar o tempo pessoal, subjetivo e dominar um tempo contínuo, objetivado, social, é que o aluno poderá perceber as dimensões do tempo em História e pensar historicamente.

0 que seria pensar historicamente?

Segundo Siman,

pensar historicamente supõe a capacidade de identificar e explicar permanências e 
rupturas entre o presente/passado efuturo, a capacidade de relacionar os acontecimentos e seus estruturantes de longa e média duração em seus ritmos diferenciados de mudança; capacidade de identificar simultaneidade de acontecimentos no tempo cronológico; capacidade de relacionar diferentes dimensões da vida social em contextos sociais diferentes. Supõe identificar, no próprio cotidiano, nas relações sociais, nas ações políticas da atualidade, a continuidade de elementos do passado, reforçando o diálogo passado/presente. Como desenvolver nos alunosesse modode pensar? Advogamos a favor da idéia de que devamos introduzi-los o mais cedo possível nessa tarefa, pois o seu desenvolvimento não é inato e, muito mais cedo do que pensamos, as crianças podem, por meios diversos, iniciarem-se em modos de pensar a História. (SIMAN, 2003: 119)

A formação do conceito de tempo, assim como a de outros conceitos, é também uma aquisição pessoal. Cada um irá construí-lo de acordo com a sua vida social e cultural. Os significados que o indivíduo atribui a um vocábulo, objeto, acontecimento ou fenômeno vai depender de sua experiência, dos conhecimentos que ele adquiriu a partir de suas vivências nas relações socioculturais e da mediação do processo de ensino e aprendizagem.. Vygotsky nos traduz claramente que a aprendizagem é um processo sócio-histórico, mediado pela cultura, pela interação entre a criança e seus pares e pela ação impulsionadora da escola.

A construção do conceito de tempo histórico e abstrato representa 0 ponto final da descontextualização dos instrumentos de mediação, quando a mente do adolescente opera com total independência do contexto concreto. Portanto, é necessário que haja antes todo um trabalho de aprendizagem, caminhando para esse entendimento altamente generalizado. É preciso que as atividades escolares favoreçam a compreensão da noção de tempo em suas variadas dimensões, ou seja, o tempo natural cíclico, o tempo biológico, o tempo psicológico, o tempo cronológico, etc. É necessário que o aluno perceba que há um tempo vivido que se relaciona com um tempo social e com um tempo bem mais complexo que é esse tempo histórico, das estruturas de longa, média ou curta duração, produto das ações e relações humanas, no qual coexistem as transformações e permanências e as perspectivas de futuro.

Quando na Educação Infantil a criança associa a idéia de tempo com figuras de sol, chuva, vento, relógio, calendário, ela está, na fase do pensamento por complexos, iniciando o trabalho para a construção do conceito de tempo. 
Figura 1

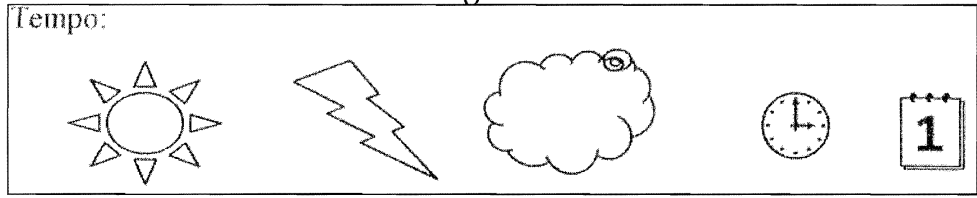

Da mesma forma, ao estudar as medições de tempo, os calendários de outras culturas, os ritmos de vida diferentes, an distinguir periodicidades, mudanças e permanências nos hábitos e costumes de vários grupos sociais, o adolescente estará caminhando para a construção abstrato-formal do conceito de tempo histórico.

Para trabalhar o conceito de tempo é importante tomar por referência: as contribuições das noções de ordenação, sucessão, duração e simultaneidade, assinalados pela teoria de Piaget, os autores da História que abordam o aspecto historiográfico do tempo: Ricoeur (1994), Pomian (1993), Reis (1994), Rojas (2001), Whitrow (1993), Bosi (1992), Bloch (2001), Braudel (1975), Novaes (1992), etc. E ainda, especialistas em Ensino de História com pesquisas sobre as idéias históricas dos alunos, ou seja, o raciocínio histórico. Assim, para esse trabalho, foram consultados pesquisadores como Aracy Antunes, Circe Bittencourt, Kátia Abud, Dennis Shemilt, Ernesta Zamboni, Hilary Cooper, Isabel Barca, Joaquín Prats, Lana Mara de Castro Siman, Maria Auxiliadora Schmidt, Mario Carretero, Peter Lee, Rosalyn Ashby, Soraia Dutra, etc; que nos ajudam a compreender a tipologia de raciocínios históricos de crianças dos anos iniciais do Ensino Fundamental; discutindo como as crianças entendem e elaboram 0 conceito de tempo.

0 estudo do tempo pode e deve ser iniciado partindo do individual para o coletivo, das vivências pessoais do aluno para o grupo social, buscando por meio da história do grupo fazer relações com outros grupos em tempos e espaços diferentes. Assim a história da vida do aluno vai aos poucos integrando uma história maior que inclui sua coletividade, seu povo e a humanidade. Como diz Siman: "na medida em que oferecemos às crianças oportunidades de tomada de consciência da historicidade de sua própria vida - e da de seu grupo de vivência - é que ela estará se iniciando no desenvolvimento do pensamento histórico e no desenvolvimento da formação da sua identidade sociocultural". (SIMAN, 2003, P. 125) 
Mas o aluno precisa também de referências, não basta só conhecer a história de sua vida e da vida de sua coletividade. É necessário saber onde e quando as mesmas histórias aconteceram. Como acentua Carretero,

para que o aluno adolescente ou pré-adolescente compreenda o significado dos diferentes períodos históricos, das eras cronológicas, etc; obviamente, deve ter desenvolvido anteriormente a compreensão do tempo pessoal e do tempo físico. Mesmo assim, a compreensão dos instrumentos de medidas é um requisito que também parece necessário. (CARRETERO, 1997, P. 39).

A criança vive em um mundo marcado pela datação - ano do nascimento, dia do aniversário, formatura, maioridade, morte, etc. Segundo Ricoeur:

o tempo-calendário revela-se indispensável à vida dos indivíduos e sociedades, pois permite a inserção da vida dispersa das sociedades em quadros permanentes, definidos por eventos religiosos, políticos, naturais, cívicos, etc. Com o calendário a experiência humana torna-se narrável. 0 historiador em sua narrativa constrói uma intriga que é uma síntese do heterogêneo, reunindo uma história complexa com múltiplos eventos. (RICOEUR apud REIS, 1994)

Constatamos então que 0 aluno necessita conhecer calendários, entender que eles são produtos da criação dos grupos humanos e podem variar conforme a diversidade cultural desses grupos. Necessita ainda aprender a medir o tempo, identificando as diferentes medidas (hora, dia, semana, mês e ano, década, século e milênio), aprender a utilizar as diferentes medidas de tempo em seu cotidiano, ser capaz de localizar períodos e acontecimentos nos séculos, e identificar os acontecimentos de um tempo próximo, vivido, assim como de um tempo histórico mais distante. Segundo Bosi (1992, P. 19) "a memória das sociedades precisa repousar em sinais inequívocos, sempre iguais a si mesmos; e o que há de mais inequívoco e sempre igual a si mesmo do que o número? Datas são números".

Relacionar os séculos, utilizando dados matemáticos, na concretude da seqüência numérica é mais fácil para a criança 1 a 100 - século I, 101 a 200 século II, 201 a 300 - século III, e daí por diante. A dificuldade aumenta 
quando é necessário fazer abstrações, relacionar a Matemática com a História, vinculando números, algarismos isolados aos acontecimentos e eventos temporais. $\mathrm{Ou}$, se temos que recorrer às convenções construídas pelos homens com base em objetivos políticos, religiosos ou outros, sem sentido concreto para eles, como o caso do referencial a.C. e d.C.

Podemos dizer sem hesitação que uma das grandes dificuldades dos alunos nos anos iniciais do Ensino Fundamental ao trabalhar com História é a de medir o tempo, principalmente localizar séculos e períodos e trabalhar datas em relação ao referencial do Calendário Cristão (a.C e d. C). Quando os passados se distanciam, o raciocínio infantil requer um trabalho operatóriomatemático de abstração e generalização complexo, mas não impossível.

Apresentaremos a seguir ${ }^{2} 0$ episódio de um trabalho de identificação de séculos e períodos com crianças de 10 e 11 anos, observado, na sala do $4^{\circ}$ Ano B, da Escola Fundamental do Centro Pedagógico da Faculdade de Educação da Universidade Federal de Minas Gerais, no ano de 2006.

\section{Foto 1: Identificando séculos}

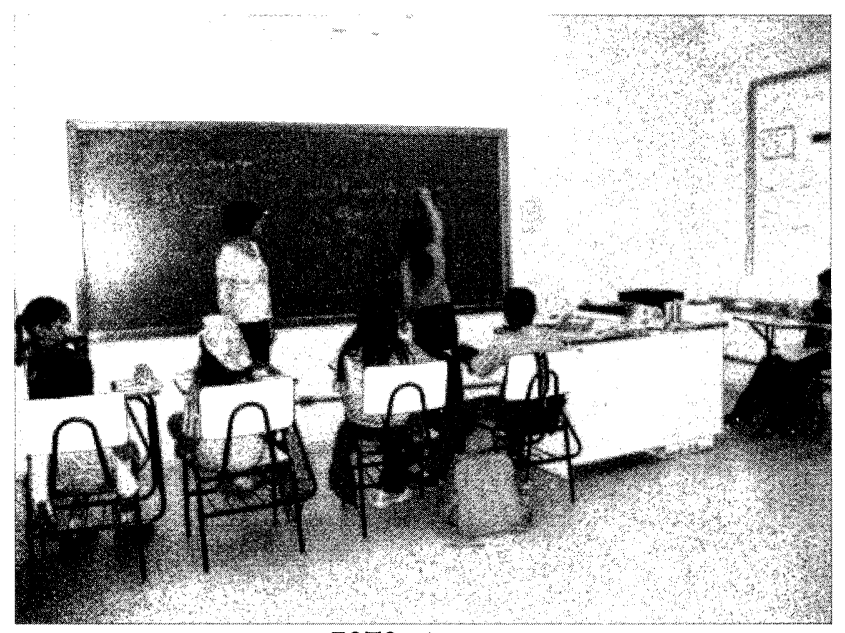

FOTO - Autora

2 Esse artigo apresenta reflexões oriundas da dissertação de Mestrado Interações Discursivas: um estudo de caso com crianças na sala de aula de História de Dilma Célia Mallard Scaldaferri (UNINCOR; 2007); realizada na sala de aula da professora e pesquisadora Cláudia Ricci no CP ( Centro Pedagógico da Faculdade de Educação, da Universidade Federal de Minas Gerais) 


\section{A) Contextualização}

0 trabalho com séculos fora iniciado em aula anterior. ". Para introduzir 0 estudo, a docente utilizou um material pedagógico produzido por ela - 0 Saquinho dos Séculos - No entanto, achamos que não seria ético fazer uma exposição detalhada desse material, uma vez que ela ainda não registrou direitos autorais sobre o mesmo e pretende fazê-lo.

No episódio ${ }^{3}$ escolhido para esta análise, os alunos estavam organizados em círculo, mas a situação exigia o uso da lousa, então, aqueles posicionados de costas para a mesma viraram para frente, no intuito de acompanhar as explicações da professora.

0 episódio teve duração de sete minutos, integrando parte da correção do "Para Casa". Ao fazer o recorte desse evento, a numeração dos turnos foi reiniciada, para facilitar o trabalho de apresentação dos dados. ${ }^{4} \mathrm{~A}$ identificação dos estudantes foi feita através da letra $\mathrm{F}$ para as mulheres e a letra $\mathrm{M}$ para os homens e o número correspondente da ordenação, segundo a lista de presença a partir da distinção entre homens e mulheres.

\section{B) Episódio}

Aula 21/03/2006:

QUADR0 17 - Séculos

\begin{tabular}{|c|c|l|}
\hline Turno & Participantes & \multicolumn{1}{|c|}{ Discurso } \\
\hline 01 & Professora & $\begin{array}{l}\text { Então ...tá certo. Oh gente... correção do para casa... (Professora tentando } \\
\text { reiniciar a correção do "Para Casa" na lousa.) }\end{array}$ \\
\hline 02 & Aluna & $\begin{array}{l}\text { professora, tinha dois "Para Casa" pra frente não era? Ah então eu confundi } \\
\text { porque eu fiz do um até o vinte e quatro.(Aluna interrompendo a professora.) }\end{array}$ \\
\hline 03 & Professora & Você começou aqui? \\
\hline 04 & Aluna & Não... eu comecei do um... \\
\hline
\end{tabular}

30 episódio foi aqui considerado uma unidade de análise, com início e fim claros, vinculada à produção de significados e conhecimentos históricos. 0 turno constitui a menor unidade de análise da sequiência da interação discursiva. (MORTIMER, 2005). 


\begin{tabular}{|c|c|c|}
\hline 05 & Aluno & professora eu só fiz um... \\
\hline 06 & Professora & $\begin{array}{l}\text { Vai... M8... começa aqui... oh. quantos anos... alguém tem dúvida disso quantos } \\
\text { anos um século tem? (Professora reinicia a atividade desenhando vinte e dois } \\
\text { quadradinhos na lousa.) }\end{array}$ \\
\hline 07 & Alunos & Cem anos. \\
\hline 08 & Professora & Cem anos. Isso todo mundo sabe? \\
\hline 09 & Alunos & Sabe. \\
\hline 10 & Professora & $\begin{array}{l}\text { Então tá. Eu não vou precisar fazer cem pauzinhos que eu fiz ontem não né? } \\
\text { Vocês fizeram pelo menos um saquinho? (Professora referindo-se ao saquinho de } \\
\text { séculos.) }\end{array}$ \\
\hline 11 & Aluno & Eu fiz... \\
\hline 12 & Professora & $\begin{array}{l}\text { Tá bom... aqui... F13. Você fez o primeiro? Então vai... ajuda aí... em que ano } \\
\text { começa esse primeiro século... século um... }\end{array}$ \\
\hline 13 & F13 & oitenta. \\
\hline 14 & Professora & An, em que ano que ele começa? (Professora manifesta estranhamento.) \\
\hline 15 & F13 & ano oitenta. \\
\hline 16 & Professora & $\begin{array}{l}\text { Ele começa no ano } 80 \text {. Gente... espera... e termina quando? (Professora impede } \\
\text { que outros alunos interrompam a resposta de F13.) }\end{array}$ \\
\hline 17 & F13 & Noventa... \\
\hline 18 & Professora & $\begin{array}{l}\text { então vamos lá... ele começa em oitenta mais um ano... oitenta e um. Mais dois... } \\
\text { oitenta e três... oitenta e quatro... oitenta e cinco... oitenta e seis... oitenta e sete... } \\
\text { oitenta e oito... oitenta e nove... noventa. Século são dez anos? Então o que que } \\
\text { está acontecendo aí ? }\end{array}$ \\
\hline 19 & Aluna & É que cada ano tem cem anos... \\
\hline
\end{tabular}




\begin{tabular}{|c|c|c|}
\hline 20 & Professora & cada ano tem cem anos? (Professora com fisionomia de espanto.) \\
\hline 21 & Alunos & is rs rs rs ( Risos e M2 antecipa a resposta baixinho.) \\
\hline 22 & Professora & $\begin{array}{l}\text { Ah... olha aqui... aqui só. } 0 \mathrm{M} 2 \text { já falou... isso aqui é uma década. Do ano } \\
\text { oitenta pro ano noventa tem dez anos... dez anos é década não é século... então } \\
\text { vamos corrigir isso aqui. Só que século escreve com s e cento escreve com c... não } \\
\text { vai confundir... }\end{array}$ \\
\hline 23 & Professora & Então vai M8. 0 século um... ele começou em que ano e ele termina em que ano? \\
\hline 24 & M8 & Ele começou em mil... \\
\hline 25 & Professora & mil? (Professora novamente espantada... tentando dar uma pista na lousa.) \\
\hline 26 & Professora & $\begin{array}{l}\text { Aqui é o um... mas aqui oh... (inaudivel). Então vamos corrigir isso M4... ih } \\
\text { gente ta difícil...F7... você quer arriscar aqui o começo? (Várias mãos } \\
\text { levantadas.) }\end{array}$ \\
\hline 27 & Aluno & Deixa eu... \\
\hline 28 & Professora & $\begin{array}{l}\text { M12... M12... M5 ... você que estava preocupado... você que perdeu a primeira } \\
\text { explicação. (Vários alunos com as mãos levantadas querem responder.) }\end{array}$ \\
\hline 29 & Aluno & Deixa eu professora? \\
\hline 30 & Professora & $\begin{array}{l}\text { Oh... eu vou escutar alguém que vai responder... mas eu quero que essa } \\
\text { pessoa explique... porque não é só falar a resposta. Eu quero a explicação. } \\
\text { Quem está com a mão levantada sabe explicar? }\end{array}$ \\
\hline 31 & Aluno & Eu sei. \\
\hline 32 & Professora & $\begin{array}{l}\text { Quem responder vai embora comigo... que é a terceira vez hoje. Aqui... eu vou } \\
\text { deixar o M11... pra todo mundo...em que ano que começa? }\end{array}$ \\
\hline 33 & M11 & Ano um... \\
\hline 34 & Professora & ano um... termina quando? \\
\hline
\end{tabular}




\begin{tabular}{|c|c|c|}
\hline 35 & M11 & Cem... \\
\hline 36 & M11 & Oh... o ano... o século tem cem anos... aí... (Inaudível.) \\
\hline 37 & Professora & Ah... começar no século... isto não é resposta. M9 você vai saber explicar? \\
\hline 38 & M9 & Vou. \\
\hline 39 & Professora & Então explica. \\
\hline 40 & M9 & $\begin{array}{l}\text { É que um século tem cem anos, ai vai começar no um porque tá no ano um. Ai o } \\
\text { último número vai ser cem porque passaram cem anos. }\end{array}$ \\
\hline 41 & Professora & $\begin{array}{l}\text { Quem quer completar... ajudar mais um pouquinho... explicar mais...(Professora } \\
\text { selecionando significados.) }\end{array}$ \\
\hline 42 & M5 & $\begin{array}{l}\text { Igual a gente estava falando agora que começou o século um por causa do } \\
\text { nascimento de Cristo... por causa disso. Aí o século um é o primeiro ano. Já } \\
\text { começou com um e como um século tem cem anos terminou no cem. }\end{array}$ \\
\hline 43 & Professora & Isso. Então... gente... (Inaudível.) \\
\hline 44 & F5 & ... teve cem anos... \\
\hline 45 & Aluna & Porque no século um vai começar com outro... (Inaudível.) \\
\hline 46 & Professora & $\begin{array}{l}\text { Olha aqui... é exatamente isso... é difícil de entender mesmo... porque é abstrato. } \\
\text { Aquilo que eu falei vocês têm que imaginar. Foram as pessoas que resolveram } \\
\text { dar esse nome... né? Eles resolveram... mais uma vez... o ano que Cristo nasceu } \\
\text { eles falaram assim: vamos chamar esse ano de ano um... não é? Então esse seria } \\
\text { o começo da contagem desse calendário. Tudo que fosse pra trás a gente vai ter o } \\
\text { cuidado de fazer o quê? }\end{array}$ \\
\hline 47 & Alunos & Antes de Cristo \\
\hline 48 & Professora & $\begin{array}{l}\text { Antes de Cristo... tá? Mas era um combinado. Por isso se eles tivessem } \\
\text { combinado... Vamos marcar quando Cristo morreu... sendo o ano trinta e três... } \\
\text { podia... né? Mas acabou sendo quando ele nasceu... ano um... ano dois... ano } \\
\text { três... Eles acompanharam a marcação do tempo pela marcação cristã tendo } \\
\text { Cristo como referência... tá? }\end{array}$ \\
\hline
\end{tabular}




\section{C) Análise do episódio}

Nos turnos de 12 a 40, a professora busca, sem êxito, encaminhar a discussão para o seguinte resultado unívoco, "0 século I compreende o período que vai do ano 1 ao ano 100".

A aluna F13 confunde década com século, 0 aluno M8 mistura século e milênio e a própria professora explicita a complexidade do problema: "olha aqui... é exatamente isso, é difícil de entender mesmo, porque é abstrato. Aquilo que eu falei vocês tem que imaginar.".

. A partir do turno 12, intervém determinada em direção a um resultado esperado, ainda que trabalhando pacientemente com as proposições nãosatisfatórias dos alunos na construção desse resultado. Aceita, temporariamente, e discute a resposta incorreta de F13, impedindo os alunos de interceptarem a colega: "Ele começa no ano 80. Gente... espera... e termina quando?"

No turno 30 , com intervenção mais firme, apresenta à turma um novo problema, não serve mais somente uma resposta descritiva, baseada em dados empíricos, ela quer uma explicação baseada em referentes teóricos, um discurso com idéias sistematizadas. "Oh... eu vou escutar alguém que vai responder... mas eu quero que essa pessoa explique, porque não é só falar a resposta. Eu quero a explicação. Quem está com a mão levantada sabe explicar?' Assim, ela manteve a narrativa sobre o conceito trabalhado, não deu respostas prontas, conseguindo conduzir as interações discursivas a um fechamento.

A partir do turno $30 \mathrm{com}$ um tom assertivo a professora conseguiu alterar a dinâmica verbal obtendo participações significativas de três estudantes, M11 inicia um raciocínio em direção ao resultado, que é completado por M9 e enriquecido por M5. Assim, sem entregar respostas prontas, ela pôde, com base nas contribuições dos três alunos, fazer, para toda turma, uma síntese teórica do conhecimento construído. A persistência da professora nos faz remontar a Bruner: "0 professor não deve esperar que a prontidão aconteça, mas aprofundar e fomentar os poderes da criança no estágio em que ela se encontra." (BRUNER 2001, P. 118). 


\section{Conclusão}

Nosso estudo de caso conseguiu evidenciar uma prática em que a produção do conceito de tempo, nas variadas dimensões, a física - o cronológico; 0 vivido; e a dimensão histórica - marcada pela relação presente / passado / futuro; foi se constituindo na alternância de palavras e contrapalavras como efeito da interação de diferentes interlocutores. Foram trabalhadas as noções de ordenação, sucessão, duração, simultaneidade, assim como as permanências e as mudanças.

0 episódio em questão foi escolhido por evidenciar a dificuldade dos alunos para compreenderem a marcação linear do tempo e identificarem diferentes durações de tempo/ano/década /século, etc. . Vimos que as crianças foram estruturando o conhecimento formal auxiliadas pela mediação da professora e dos colegas: trabalharam o conceito de século e década; vincularam a contagem do tempo ao calendário cristão. Nesse sentido foi significativa a explicação final da professora acerca dos marcos de referência a.C. e d. C.; para que as crianças percebessem que essa é uma dentre outras convenções construídas pelos homens para facilitar o entendimento da datação histórica.

Podemos dizer que as intervenções pedagógicas favoreceram 0 raciocínio das crianças sobre a complexidade da temporalidade histórica, mas não que resultaram num domínio nesse sentido. Reportando a Piaget, diríamos que nessa fase elas ainda estão muito dependentes do contexto concreto. Pensar historicamente, como assinala Siman, requer um grau elevado da capacidade de abstração e é um processo de construção que será adquirido com a ajuda da instrução escolar ao longo da adolescência.

Acreditamos, respeitando Piaget, que a possibilidade de os alunos raciocinarem historicamente em relação ao conceito de tempo depende do desenvolvimento cognitivo. É necessário descentrar, comparar, relacionar abstrair, generalizar, formalizar etc; funções intelectuais do processo de maturação de cada aluno que são adquiridas em momentos diferentes por crianças e adolescentes. Mas, levando em consideração o que pudemos perceber nas interações verbais da sala do $4^{\circ}$ ano $\mathrm{B}$, onde várias dimensões do conceito de tempo não foram ensinadas, mas construídas com as crianças de forma compartilhada, argumentamos a favor da teoria de Vygotsky, sobre a relação 
ensino-aperendizagem e desenvolvimento: a boa aprendizagem é aquela que está à frente do desenvolvimento. As crianças devem ser introduzidas no desenvolvimento das operações e raciocínios exigidos pela natureza do pensamento histórico, pois a instrução escolar, com a mediação do professor e dos colegas, pode acelerar o curso do desenvolvimento cognitivo. Cabe ao professor criar situações e intervenções que ativem o processo de construção do conceito de tempo.

\section{Referências}

ABUD, Kátia Maria, Temporalidade e didática da história. In: Anais III encontro nacional de pesquisadores do ensino de bistória, Campinas, SP: Gráfica da FE/UNICAMP, 1999, p. 31-36.1995.

ANTUNES, Aracy do Rego e outros. Estudos Sociais - Teoria e Prática, Rio de Janeiro:Access Editora, 1993.

BARCA, Isabel. O pensamento histórico dos jovens. BRAGA: Ed. Universidade do Minho,2000.

BITTENCOURT, Circe Maria Fernandes. Ensino de História: fundamentos e métodos, SãoPaulo: Cortez, 2004.

BLOCH, Marc, A história, os homens e o tempo. In: Introdução à História, Coleção Saber, p. $25-46$..

BOSI, A, 0 tempo e os tempos. In: NOVAES, A. (org), Tempo e História, SP: Cia. Das Letras, 1992.

BRUNER, Jerome S. Uma Nova Teoria da Aprendizagem, Rio de Janeiro: Bloch, 1973. BRUNER, Jerome. A Cultura da Educação, Porto Alegre: Artmed, 2001.

CARRETERO, Mário e VOSS, James F. Aprender y pensar la historia ,Buenos Aires: Amorrortu, 2004.

CARRETER0, Mario. Construir e Ensinar - As Ciências Sociais e a História. São Paulo:Artmed, 1997.

CARRETER0, Mario e LIMÓN, Margarita. La construcción del conocimiento histórico.Algunas cuestiones pendientes de investigación, Cuadernos de Pedagogía, 
221, p. 24-26.trad. Bruno Magne - Porto Alegre: Artmed, 2000.

DUTRA, Soraia Freitas. As crianças e o desenvolvimento da temporalidade histórica . Tese de mestrado, Faculdade de Educação da UFMG, Belo Horizonte: UFMG, 2003.

GOUREVITCH, A. Y. 0 tempo como problema da História Cultural. In: RICOEUR, P. (Org.), As culturas e o tempo. Petrópolis: Vozes, 1975.

LE GOFF, Jacques et alli. A Nova História, Lisboa: Edições 70, 1984.

LEE, Peter ; SHEMILT, Dennis. A Scaffold, not a cage progression and progression models.in history. In: Teaching History, $\mathrm{n}^{\circ} 113$, sd.

LEE, Peter et alli. Las ideas de los ninõs sobre la historia. In: CARRETER0, Mario, Aprender y pensar la bistoria. Buenos Aires: Amorrortu, 2004.

PARANÁ. Secretária de Estado da Educação - Superintendência de Educação, Orientação Curriculares de História .Curitiba: DEM, 2006.

MORTIMER, Eduardo Fleury ; SMOLKA, Ana Luíza. (orgs.) Linguagem, Cultura e Cognição: Reflexão para o Ensino em Sala de Aula. Belo Horizonte: Autêntica, 2001. PIAGET, Jean. A Noção de Tempo na Criança, Rio de Janeiro: Record, 1975.

PIAGET, Jean - El desarrollo de la Noción de Tiempo en el Niño, México, Fondo de Cultura Económica, 1978.

POMIAN. K. "Tempo/Temporalidade", Enciclopédia Einaudi, vol. 29, Lisboa: Imprensa Nacional - Casa da Moeda, 1993, p. 10-91.

POMIAN. K. "Periodização", Enciclopédia Einaudi, vol. 29, Lisboa, Imprensa Nacional - Casa da Moeda, 1993, p.164-213.

REIS, J.C. Tempo, história e evasão. Campinas: Papirus, 1994.

RICOUER, P. (Org.). As culturas e o tempo. Petrópolis: Vozes, 1975.

RICOUER, Paul. Tempo e narrativa. Campinas: Papirus, 1994.

ROJAS, Carlos A. Aguirre, A longa duração no espelho: Para além do tempo vivido e do tempo "expropriado", In: Tempo, duração e civilização: Percursos Braudelianos. SP: Editora Cortez, 2001.

SANTO AGOSTINHO. Confissões. Porto: Liv. Apost. da Imprensa. Livro 1, p. 346. 
SCHMIDT, Maria Auxiliadora, Construindo Conceitos no Ensino de História: A capturalógica da realidade social. In: História e ensino. Paraná: Editora UEL, 1999, v.5, p.147-164.

SIMAN, Lana Mara de Castro. A Construção do Conhecimento e do Raciocínio Histórico e Cidadania nas Crianças, In: Anais do IV Encontro Nacional de Pesquisadores do Ensino deHistória/ANPUH/RS. Ijuí: Editora Unijuí, 1999, p. 598-605.

SIMAN, Lana Mara de Castro. A sala de aula de História como espaço de produção de sentidos e novos significados. Anais do IV Encontro Nacional: Perspectivas do Ensino de História. Londrina: Atrito Art, 2005, p. 93-109.

SIMAN, Lana Mara de Castro. A Temporalidade Histórica como Categoria Central do Pensamento Histórico: Desafios para o Ensino e a Aprendizagem. In: ROSSI, Vera L. Sabongi ; ZAMBONI, Ernesta (orgs.). Quanto tempo o tempo tem! Campinas: Alínea, 2003, p. 109-143.

SIMAN, L. M. C. 0 Papel da ação mediada na construção do conhecimento histórico e no desenvolvimento do seu raciocínio. In: VII Jornada de Ensino de História e Educação, 2002, Passo Fundo, RS. História e construção do conhecimento. Passo Fundo: EDIUPF, 2002.

SIMAN, Lana Mara C.; DUTRA, Soraia F. Tempo: uma categoria central do pensamento e da ação humana. In Educação Especial Inclusiva. Belo Horizonte: PUC-MINAS, 2005, V.1, p.44-55.

VYGOTSKY, L. S. Pensamento e Linguagem. São Paulo: Martins Fontes, 1995.

WHITROW, G.J. Consciência do tempo. In: O tempo na História: concepção de tempo da pré-bistória aos nossos dias. Rio de Janeiro: Jorge Zahar, 1993, p. 15-23. 


\section{Conceptions of Time and history teaching}

Abstract

Time, a basic and structural concept in historical thinking is reviewed in our work. We evaluate the acquisition of such concept by students from Elementary School. Although the concept of time is already part of the Brazilian's Elementary School curriculum, many teachers find it difficult to work with this subject because of its complexity and the need of high abstraction for its understanding. We hope our work could be used as an analytical instrument by other researchers to help studying the learning of the concept of time by students in the fist years of education.

Key-words: histirical time; history teaching; historical reasoning. 